\title{
TEC prediction performance of the IRI-2012 model over Ethiopia during the rising phase of solar cycle 24 (2009-2011)
}

\author{
Yekoye Asmare Tariku
}

\begin{abstract}
This paper discusses the performance of the latest version of the International Reference lonosphere (IRI-2012) model for estimating the vertical total electron content (VTEC) variation over Ethiopian regions during the rising phase of solar cycle 24 (2009-2011). Ground-based Global Positioning System (GPS) VTEC data, inferred from dual-frequency GPS receivers installed at Bahir Dar (geographic latitude $11.6^{\circ} \mathrm{N}$ and longitude $37.35^{\circ} \mathrm{E}$, geomagnetic latitude $2.64^{\circ} \mathrm{N}$ and longitude $108.94^{\circ} \mathrm{E}$ ), Nazret (geographic latitude $8.57^{\circ} \mathrm{N}$ and longitude $39.29^{\circ} \mathrm{E}$, geomagnetic latitude $-0.25^{\circ} \mathrm{N}$ and longitude $111.01^{\circ} \mathrm{E}$ ), and Robe (geographic latitude $7.11^{\circ} \mathrm{N}$ and longitude $40.03^{\circ} \mathrm{E}$, geomagnetic latitude $-1.69^{\circ} \mathrm{N}$ and longitude $111.78^{\circ} \mathrm{E}$ ), are compared to diurnal, monthly, and seasonal VTEC variations obtained with the IRI-2012 model. It is shown that the variability of the diurnal VTEC is minimal at predawn hours (near 0300 UT, 0600 LT) and maximal between roughly 1000 and 1300 UT (1300-1600 LT) for both the experimental data and the model. Minimum seasonal VTEC values are observed for the June solstice during the period of 2009-2011. Moreover, it is shown that the model better estimates diurnal VTEC values just after the midnight hours (0000-0300 UT, 0300-0600 LT). The modeled monthly and seasonal VTEC values are larger than the corresponding measured values during the period of 2009-2010 when all options for the topside electron density are used. An important finding of this study is that the overestimation of VTEC values derived from the model decreases as the Sun transitions from very low to high solar activity. Moreover, it is generally better to use the model with the NeQuick option for the topside electron density when estimating diurnal, monthly, and seasonal VTEC variations.
\end{abstract}

Keywords: GPS-VTEC; IRI-2012 VTEC; Solar cycle; Equatorial ionosphere

\section{Background}

The ionosphere is a highly variable and complex physical system where ions and electrons are present in quantities sufficient to affect the propagation of radio waves (Matsushita and Campbell 1967). Free electrons populating this region of the atmosphere affect the propagation of the radio signals, changing their speed and direction of travel. Hence, the accumulation of electrons affects the electromagnetic waves that pass through the ionosphere by inducing an additional transmission time delay (Klobuchar et al. 1996). This delay is directly proportional to the number of free electrons in a cylinder of unit cross-section along the signal path extending from the satellite to the receiver on the ground and inversely

Correspondence: yekoye2002@gmail.com

Department of Physics, University of Ambo, Ambo, P.O. Box 19, Ethiopia proportional to the square of the frequency of the transionospheric radio wave (Hofmann-Wellenhof et al. 1992; Misra and Enge 2006). Due to the unique geometry of the magnetic field, these phenomena are most pronounced in low-latitude and equatorial regions such as Ethiopia. In such regions, the plasma density in the ionosphere shows significant variations with time of day, latitude, longitude, season, and solar and geomagnetic activity, which can result in a variation of different parameters such as total electron content (TEC). The daytime equatorial and low-latitude ionosphere is characterized by an $\mathrm{F}$ region electron density trough at the geomagnetic equator and two crests within $\pm 20^{\circ}$ magnetic latitude. The $\mathrm{F}$ region density, in particular, represents the greatest contribution to the maximum TEC in 
the ionosphere, which can significantly affect radio wave propagation.

It is apparent that most of our knowledge of the ionosphere comes from remote sensing techniques. As a result, ground- or space-based instruments have been employed to gain a better understanding of the ionosphere. One of the tools that have been used extensively for such purposes is the Global Positioning System (GPS). For ionospheric characterization, GPS observations allow the study of dispersive propagation properties of the ionosphere for trans-ionospheric radio wave propagation. The signals from the GPS satellites travel through the ionosphere on their way to receivers on the ground; however, the free electrons accumulated in this region of the atmosphere affect the propagation of the signals by changing their velocity and direction of motion. Consequently, according to Ioannides and Strangeways (2000), GPS signals cannot travel along a perfectly straight line and reach the desired position in the time expected. According to Reddy (2002), this delay in the GPS signal is directly proportional to the TEC. Hence, TEC is considered the major cause of ionospheric effects on the radio wave propagation system. It can be expressed in total electron content units (TECUs) as follows:

$$
N_{T}=\int_{R}^{S} N_{e} d s
$$

where 1 TECU $=1 \times 10^{16}$ electrons $\mathrm{m}^{-2}$.

The TEC in the ionosphere shows diurnal, monthly, and seasonal variability. It also varies with the activity of the Sun, with highest TEC values generally occurring during periods of high solar activity, while the lowest values are observed during periods of low solar activity. The GPSderived TEC (GPS-TEC) utilized in this study can be obtained employing pseudorange and carrier phase measurements given as follows.

The TEC inferred from the pseudorange measurement is given by:

$$
\operatorname{TEC}_{P}=\frac{1}{40.3}\left[\frac{f_{1}^{2} f_{2}^{2}}{f_{1}^{2}-f_{2}^{2}}\right]\left(P_{2}-P_{1}\right) .
$$

Similarly, the TEC from carrier phase measurement can be given as:

$$
\mathrm{TEC}_{\Phi}=\frac{1}{40.3}\left[\frac{f_{1}^{2} f_{2}^{2}}{f_{1}^{2}-f_{2}^{2}}\right]\left(\Phi_{1}-\Phi_{2}\right)
$$

where $f_{1}$ and $f_{2}$ can be related with the fundamental frequency, $f_{o}=10.23 \mathrm{MHz}$

$$
\begin{aligned}
& f_{1}=154 f_{o}=1575.42 \mathrm{MHz} \text { and } \\
& f_{2}=120 f_{o}=1227.60 \mathrm{MHz} .
\end{aligned}
$$

In spite of some ambiguity, according to Gao and Liu (2002), TEC from carrier phase measurements has relatively less noise. On the other hand, TEC from code pseudorange measurements is free of ambiguity but with relatively more noise. Hence, to solve this problem, a linear combination between carrier phase and pseudorange measurements has been employed. This combination is used to reduce the pseudorange noise by smoothing GPS pseudorange data with carrier phase measurements (Hansen et al. 2000). The Sardon et al. (1994) approach of removing differential instrument biases was then followed for accurate TEC estimation. This is necessary because satellites and receivers for the GPS observables are biased on the instrumental delays (Norsuzila et al. 2009). Consequently, according to Klobuchar et al. (1996), linearly combining both code pseudorange and carrier phase measurements for the same satellite pass is supposed to increase the accuracy of TEC. This resultant absolute TEC is the GPS-derived slant total electron content (STEC) along the signal path between the satellite and the receiver on the ground. To avoid a dependence of the STEC on the ray path geometry from the satellite to the receiver through the ionosphere, the STEC has to be converted to the vertical total electron content (VTEC). In addition, the VTEC is considered a more compact parameter for characterization of the TEC over a given receiver position and used as a good indicator for the overall ionization of Earth's ionosphere (Komjathy and Langley 1996). Hence, using a mapping function, the STEC is converted to the VTEC by assuming that the ionosphere is equivalent to a thin shell encircling the Earth with the same center as that of the Earth (Mannucci et al. 1998). Therefore, in terms of zenith angle $X^{\prime}$ at the ionospheric piercing point (IPP) and zenith angle $X$ at the receiver position on the ground, the relationship between STEC and VTEC can be given by:

$$
\mathrm{VTEC}=\operatorname{STEC}\left(\cos x^{\prime}\right),
$$

where

$$
\chi^{\prime}=\arcsin \left[\frac{R_{e}}{R_{e}+h_{m}} \sin \chi\right] .
$$

Substituting Eq. (6) into Eq. (5) and rearranging, we get:

$$
\mathrm{VTEC}=\operatorname{STEC}\left\{\cos \left[\arcsin \left(\frac{R_{e}}{R_{e}+h_{m}} \sin X\right)\right]\right\} .
$$

Here, $R_{e}$ is Earth's radius in kilometers and $h_{m}$ is the height of maximum electron density at the F2 peak, 
which is commonly taken to be $350 \mathrm{~km}$ (Mannucci et al. 1998; Norsuzila et al. 2009).

In addition to GPS, there are other empirical models that are very important for estimating ionospheric characteristics of a specific region at a specific time, latitude, and longitude, where measured values are not available. For instance, for successful radio communication, it is essential to predict the behavior of the ionospheric region that will affect a given radio communication circuit. Such a prediction can identify the time periods, path regions, and sections of high frequency bands that will allow or disrupt the use of the selected high frequency communication circuit. For such purposes, empirical models play a major role for the description of ionospheric conditions. Today, these models are used not only for long-term predictions but also for the real-time description of ionospheric conditions. One of the most widely used empirical models is the International Reference Ionosphere (IRI) model (Bilitza 1990; Rawer et al. 1978). The IRI model continually undergoes improvements when new data and new techniques are available and this process has resulted in several versions of the model. The first version was released in 1978, which was followed by progressively improved versions in 1986, 1990, and 1995 (Bilitza, 1990; Rawer et al. 1978). A new version of the model (IRI-2012) was released in 2013. For a given location, time, and date, the IRI-2012 model provides the monthly average electron density, electron and ion temperature, ion composition, and electron content in an altitude range from about 50 to $2000 \mathrm{~km}$ (Bilitza et al. 2014; http://IRImodel.org).

Utilizing the model and GPS-TEC data, researchers have conducted numerous studies over various equatorial and low-latitude regions. Based on their findings, these researchers have stated their views concerning the TEC prediction performance of the model in specific ionospheric regions during specific times. Ezquer et al. (2014), for instance, noted that IRI-2012 predictions show significant deviations from experimental values during the period of 2008-2009 for a station placed at the southern crest of the equatorial anomaly in the American region. Olwendo et al. (2012a) also noted that seasonal average IRI-2007 TEC values were higher than the GPS-TEC data for the period of 2009-2011 over different regions in Kenya. In addition, Olwendo et al. (2012b) reported that the IRI-2007 TEC is too high for all seasons except for the March equinox (where there seems to be good agreement between observation and model) during the lowest solar activity phase (2009-2010). The report of Nigussie et al. (2013) on the validation of the NeQuick 2 and IRI-2007 models for the East African equatorial region also showed that the IRI-2007 model generally overestimated the observed VTEC during the solar minimum year (2007-2009). Asmare et al. (2014) and Tariku (2015) attempted to see patterns in both measured and modeled VTEC variations during low and high solar activity phases by considering eight GPS stations installed recently in different regions of Ethiopia. Asmare et al. (2014) showed that the model entirely overestimated both monthly and seasonal VTEC values during phases of low solar activity. In addition, the model performance in estimating diurnal VTEC variations was found to be better during low solar activity phases than during high solar activity phases. Abdu et al. (1996), Kakinami et al. (2012), Kumar et al. (2015), and McNamara (1985) attempted to describe the model's capacity to estimate the TEC in low- and mid-latitude regions. However, so far nobody has conducted a study to investigate patterns of VTEC variation over Ethiopian regions during the rising phase of solar cycle 24. As a result, in this study, diurnal, monthly, and seasonal VTEC variations, and the VTEC prediction capability of IRI-2012 are presented in the rising phase of solar cycle 24 (2009-2011), using all three options for determining topside electron density.

\section{Methods}

The GPS-TEC data used in this study were derived from the dual-frequency GPS receiver stations shown in Fig. 1 during the period of 2009-2011. Table 1 also shows the geographic and geomagnetic coordinates and dip angles of the stations. The method proposed by Ciraolo et al. (2007) was used to calibrate the required GPS-TEC data obtained from the UNAVCO website (see http://facility.unavco.org/data/dai2/app/dai2.html). The data calibration process was carried out in 5-min intervals, and an elevation cut-off $20^{\circ}$ was used to reduce the error emanating from multipath effects. The corresponding modeled VTEC values were produced by the IRI-2012 model using the three available options (NeQuick, IRI01, and IRI2001) for topside electron density and ABT-2009 for bottomside thickness. The CCIR option was used for calculating the F2 peak density. For more information, see the model website (http://omniweb.gsfc.nasa.gov/vitmo/ iri2012-vitmo.html), accessed for the period of 3-12 June 2015.

To study the pattern of hour-to-hour variations of VTEC for each month while validating the model, magnetically quiet days (based on the availability of GPS-TEC data) representing each month were selected for 2010 from Robe station. Similarly, to compare the patterns of diurnal VTEC variations during the period of 2009-2011, TEC data from sample days representing the solstice and equinoctial months from Nazret station were employed. For monthly and seasonal VTEC variations, GPS and model TEC data collected at Bahir Dar station during 2010 and at Nazret station during 2009 and 2011 were considered. To study monthly 


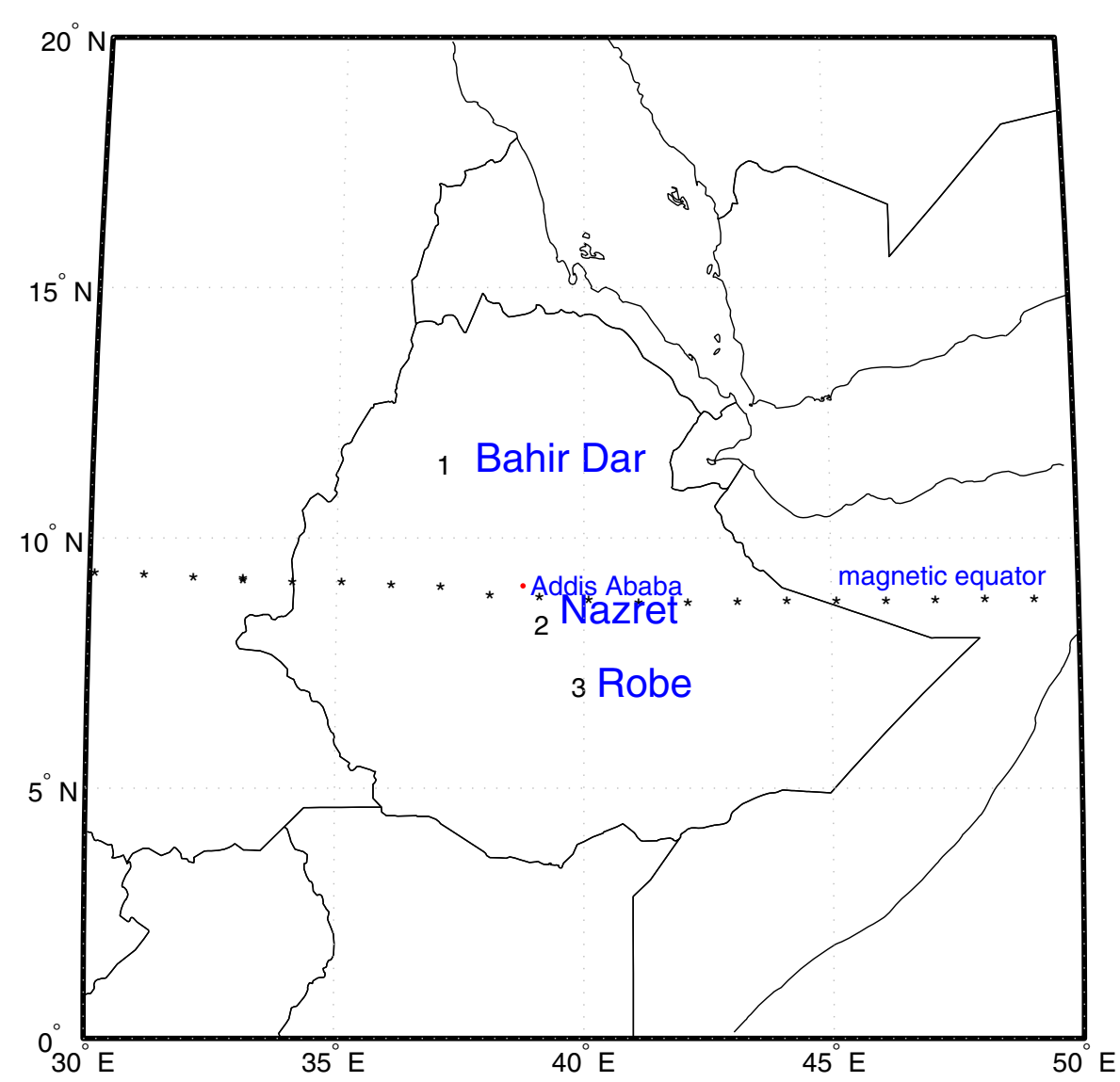

Fig. 1 Locations of the GPS receivers used for this study

VTEC variations and model performance during the period of 2009-2011, the hour-to-hour measured and modeled VTEC values were added and averaged for all magnetically quiet days in each month. Similar to the technique used for studying the monthly VTEC variations, the hour-to-hour VTEC values were added for each season and averaged for 2009, 2010, and 2011, to observe the pattern of seasonal VTEC variations while validating the model. The seasons are classified as March equinox (February, March, and April), June solstice (May, June, and July), September equinox (August, September, and October), and December solstice (November, December, and January). For a clear validation of the model, the absolute differences between the diurnal, monthly, and seasonal GPS-VTEC data and the corresponding IRI-2012 VTEC values were determined. The differences were computed by subtracting the experimental VTEC values from the model data.

\section{Results and discussion}

Diurnal variation of VTEC and performance of the IRI-2012 model

The results for the diurnal VTEC variations are shown in Figs. 2, 3, and 4. The hour-to-hour VTEC values attained their peak mostly between 1000 and 1300 UT (1300 and $1600 \mathrm{LT}$ ) and decreased in the nighttime hours, reaching a minimum after midnight around 0300 UT (0600 LT). In addition, the peak hour-to-hour values are enhanced in the equinoctial months and reach a

Table 1 Geographic and geomagnetic coordinates and dip angles of the GPS stations

\begin{tabular}{lllll}
\hline Station & Code & $\begin{array}{l}\text { Geographic Coordinates } \\
\text { Lat. }\left({ }^{\circ} \mathrm{N}\right), \text { Long. }\left({ }^{\circ} \mathrm{E}\right)\end{array}$ & $\begin{array}{l}\text { Magnetic Coordinates } \\
\text { Lat. }\left({ }^{\circ} \mathrm{N}\right), \text { Long. }\left({ }^{\circ} \mathrm{E}\right)\end{array}$ & Dip angle \\
\hline Arba Minch & ARMI & $(6.06,37.56)$ & $(-3.03,109.29)$ & -5.7 \\
Bahir Dar & BDAR & $(11.6,37.35)$ & $(2.64,108.97)$ & 8.03 \\
Nazret & NAZR & $(8.57,39.29)$ & $(-0.25,111.01)$ & 1.19 \\
Robe & ROBE & $(7.11,40.03)$ & $(-1.69,111.78)$ & -2.11 \\
\hline
\end{tabular}




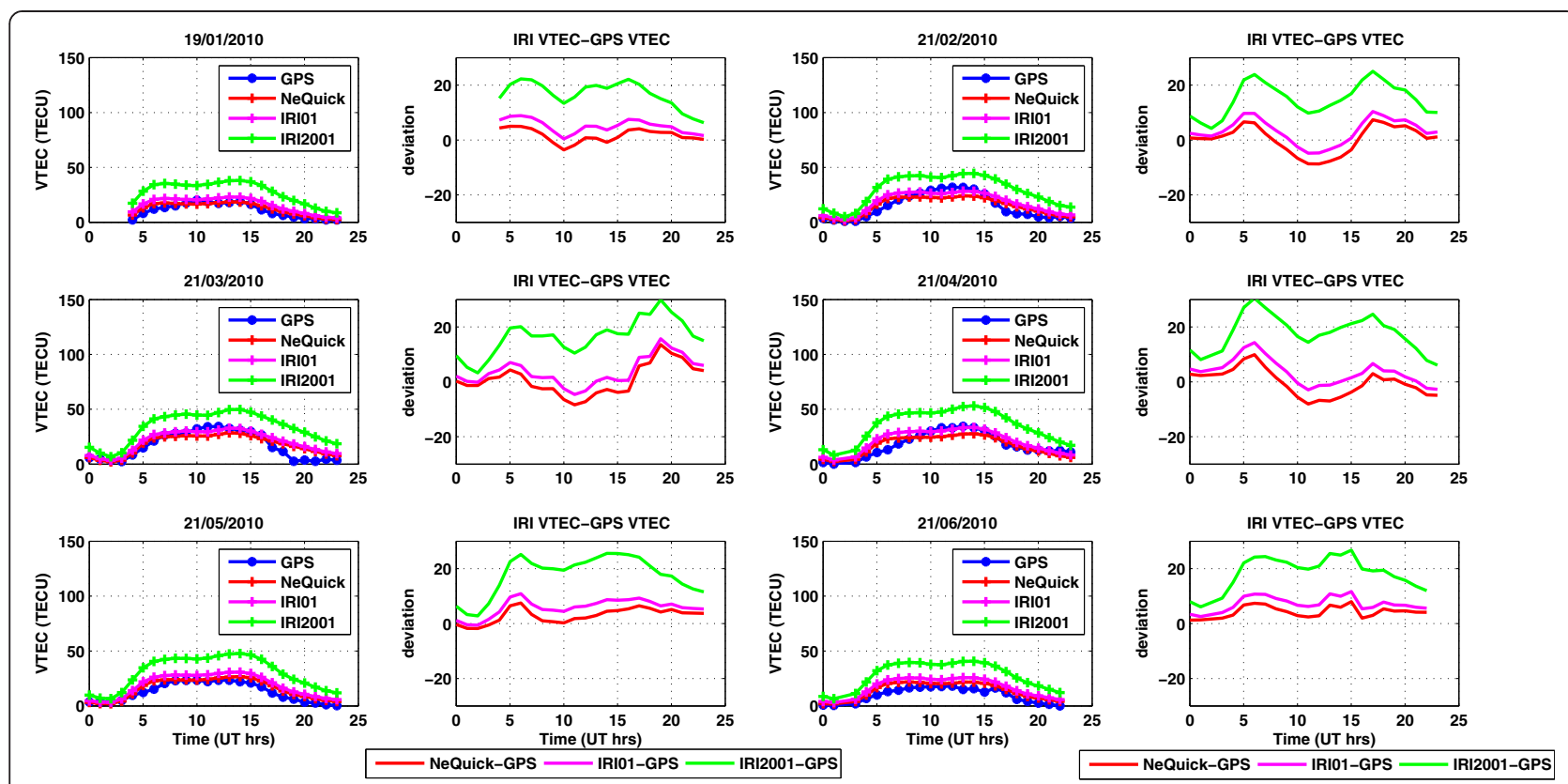

Fig. 2 Diurnal hourly VTEC variations and validation of the IRI-2012 model over Robe (station 3) for January-June 2010

minimum during the June solstice months. For instance, results obtained from Robe station on the same day in 2010 show that the highest and lowest peak hourly VTEC values of about 40 and 18 TECU were recorded in October and June, respectively. Similarly, the highest modeled VTEC value of about 53 TECU is observed for April when the IRI-2001 option for topside electron density is used. On the other hand, the lowest modeled VTEC value of about 22
TECU is observed for June when the NeQuick option is used (see Figs. 2 and 3). Moreover, as shown in Fig. 4, both measured and modeled VTEC values increase as solar activity increases. For example, peak measured VTEC values of about 24, 29, and 47 TECU were recorded on the same day in an equinoctial month in 2009, 2010, and 2011, respectively. Similarly, when the NeQuick option is used, peak modeled VTEC values of about 26, 29, and 40 TECU

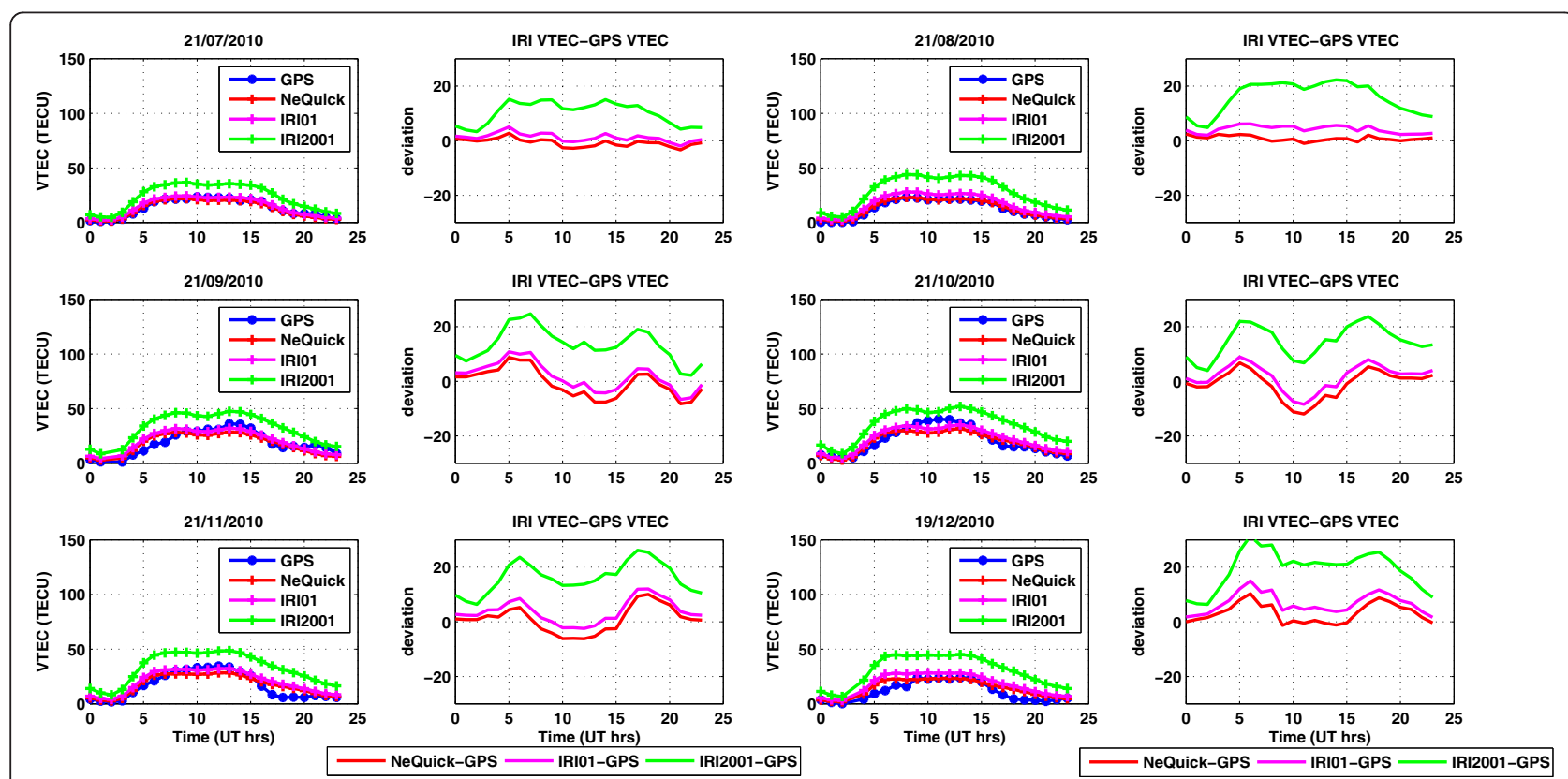

Fig. 3 Diurnal hourly VTEC variations and validation of the IRI-2012 model over Robe (station 3) for July-December 2010 


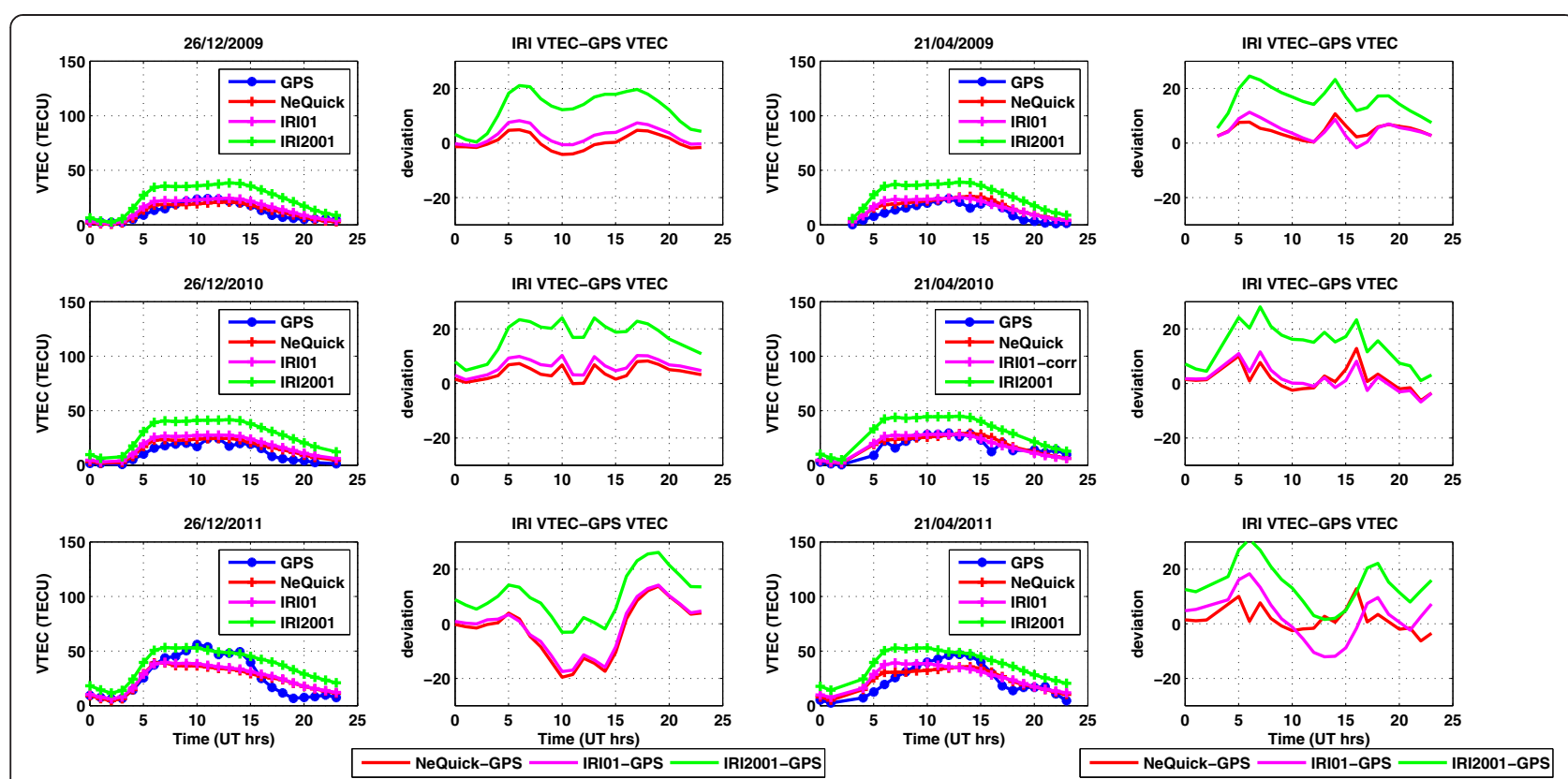

Fig. 4 Diurnal VTEC variations and validation of the IRI-2012 model over Nazret (station 2) during the period of 2009-2011

are observed for the same day in the same equinoctial month in 2009, 2010, and 2011, respectively.

Moreover, the model is generally found to overestimate VTEC values for most hours as depicted in Figs. 2, 3 , and 4 . On the other hand, the model is found to underestimate VTEC values between 0900 and 1300 UT (1300 and $1600 \mathrm{LT}$ ), especially in the equinoctial months, when the NeQuick and IRI01 options are used. The VTEC values were found to be well modeled for the after-midnight hours (0000-0300 UT, 0300-0600 LT). In general, the modeled VTEC values show good agreement for all months and seasons when the NeQuick and IRI01 options are used, especially for 2009 and 2010 (see Figs. 2, 3, and 4). As solar activity increases, the model with the IRI-2001 option tends to estimate the VTEC values well, especially for the noontime hours (see Fig. 4). Prior to this study, Kumar et al. (2014) showed that VTEC values derived from the IRI-2012 model with the NeQuick and IRI01 options for topside electron density are in a good agreement with the GPS VTEC values for 2010 over a low-latitude region in Singapore.

Some of the observed discrepancies between the experimental and modeled VTEC values, especially for the equinox months in the time interval between 0900 and 1300 UT (1200-1600 LT), could be due to differences in slab thickness between the model and experimental data (Gulyaeva et al. 2004; Nigussie et al. 2013; Rios et al. 2007). For instance, Rios et al. (2007) employing the IRI-2001 model showed that the IRI-predicted slab thickness was higher than the measured values except between 1000 and 1400 LT, which can result in VTEC fluctuations. A similar event is clearly observed in Figs. 2, 3, and 4. As shown in the figures, except between 0900 and 1300 UT (1200 and $1600 \mathrm{LT})$, during which underestimation of the modeled VTEC values is observed, the model generally tends to overestimate the VTEC values for the period of 2010-2011 when the NeQuick and IRI01 options are used. As noted by other researchers (e.g., Luhr and Xiong 2010; Sethi et al. 2011; Oyekola 2012), the overestimation of daytime VTEC by the IRI-2012 model may be attributed to the model's overestimation of the equatorial vertical drift. Oyekola (2012), for instance, described a linkage between modeled TEC and vertical drift. It has been shown that the patterns of minimum diurnal IRI-model-predicted TEC observed in pre-sunrise hours for the four seasons almost coincides with the period when vertical drift reaches a predawn minimum over the equatorial region. This effect can be clearly observed in Figs. 2, 3, and 4. The VTEC overestimation could also be due to a decrease of the flux of extreme ultraviolet (EUV) radiation (Kakinami et al. 2012). As shown in Figs. 2, 3, and 4, when the EUV flux increases around noontime, the overestimation capacity of the model decreases, especially when using the NeQuick and IRI01 options for the topside electron density.

\section{Monthly variation of VTEC and performance of the IRI-2012 model}

The results for monthly VTEC variations are shown in Figs. 5, 6, and 7. The results indicate that the highest measured and modeled monthly VTEC values are observed for October during 2009 and 2010 (top left panels of Figs. 5 and 6). On the other hand, the lowest values 


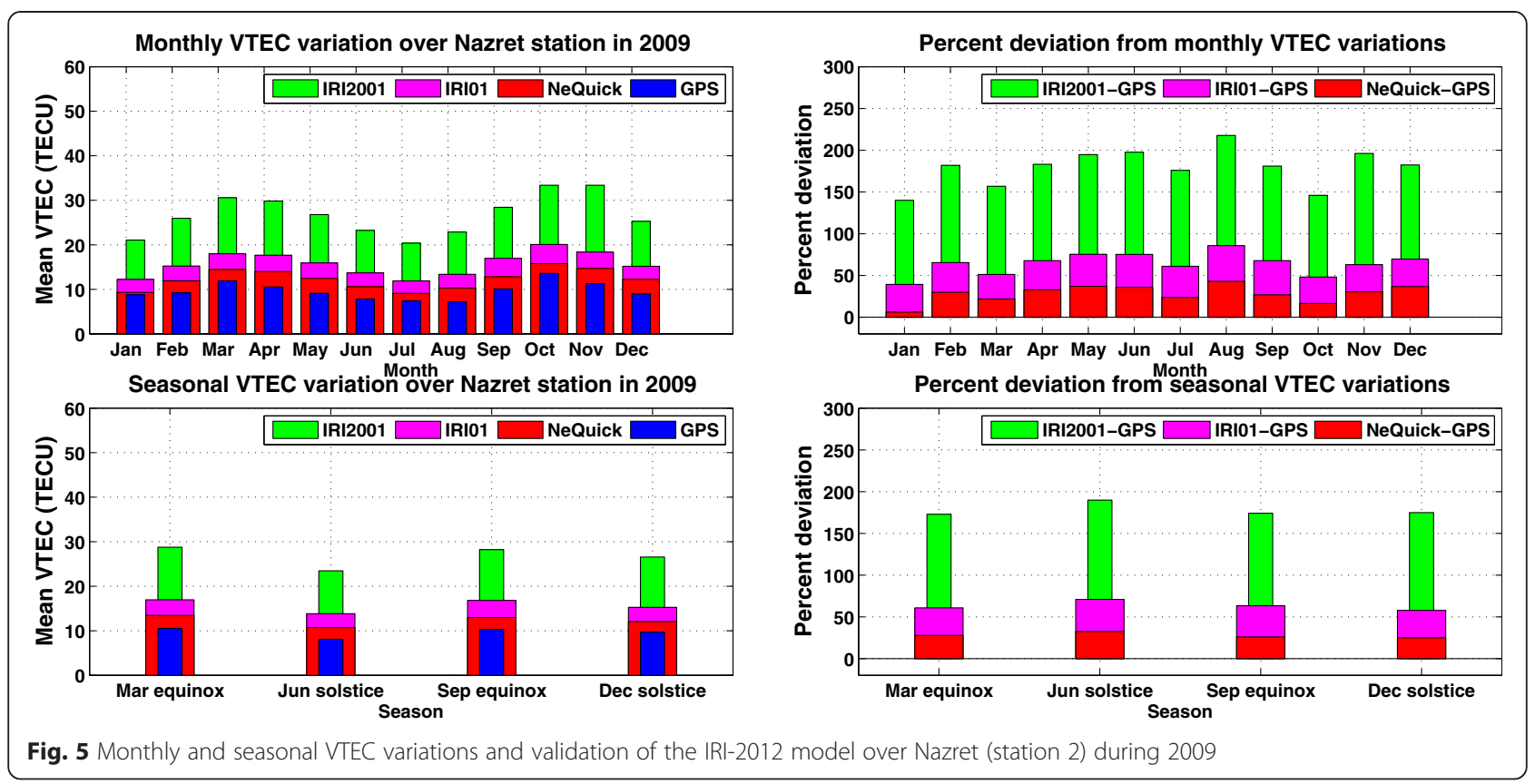

are observed for both experimental data and the model for July during 2009 and June during 2010. During 2011, the lowest and highest measured monthly VTEC values are observed for July and November, respectively. In addition, the measured VTEC values observed during 2011 are generally larger (by more than a factor of two) than those of the corresponding VTEC values observed in 2009 over the same station (Nazret; top left panels of Figs. 5 and 7).

The modeled monthly VTEC values are larger than the corresponding measured values for all months in 2009 and
2010. For instance, when the NeQuick and IRI-2001 options are used, the largest deviations observed for August 2009 will be around 43 and $210 \%$, respectively (top right panel of Fig. 5). During 2010, there is a good agreement between the modeled and experimental monthly VTEC values for March (especially in using the NeQuick option). However, in other months, the model is found to entirely overestimate the monthly VTEC values, with the highest overestimation (by about $140 \%$ ) observed for June when the IRI-2001 option is used. However, overestimation of the
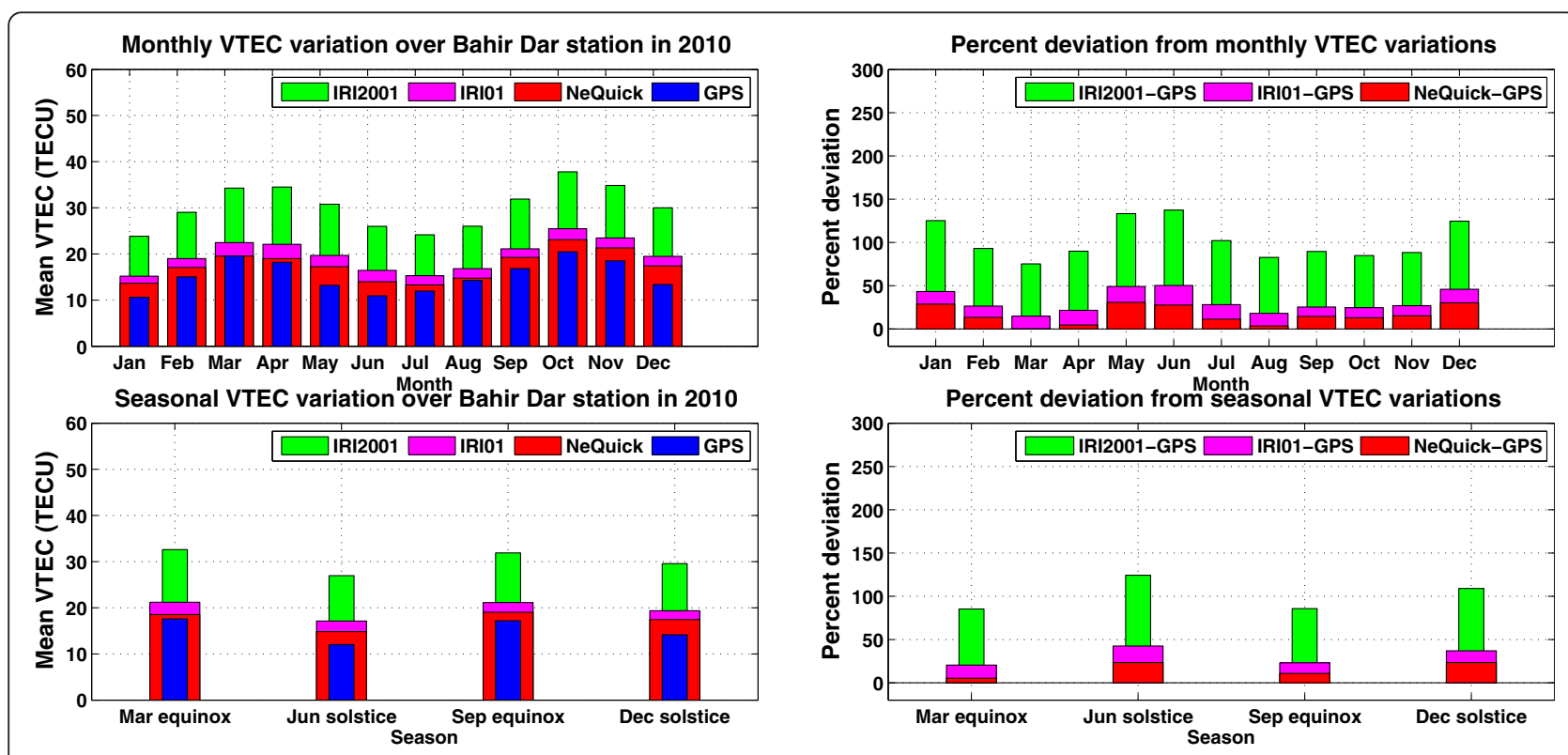

Fig. 6 Monthly and seasonal VTEC variations and validation of the IRI-2012 model over Bahir Dar (station 1) during 2010 

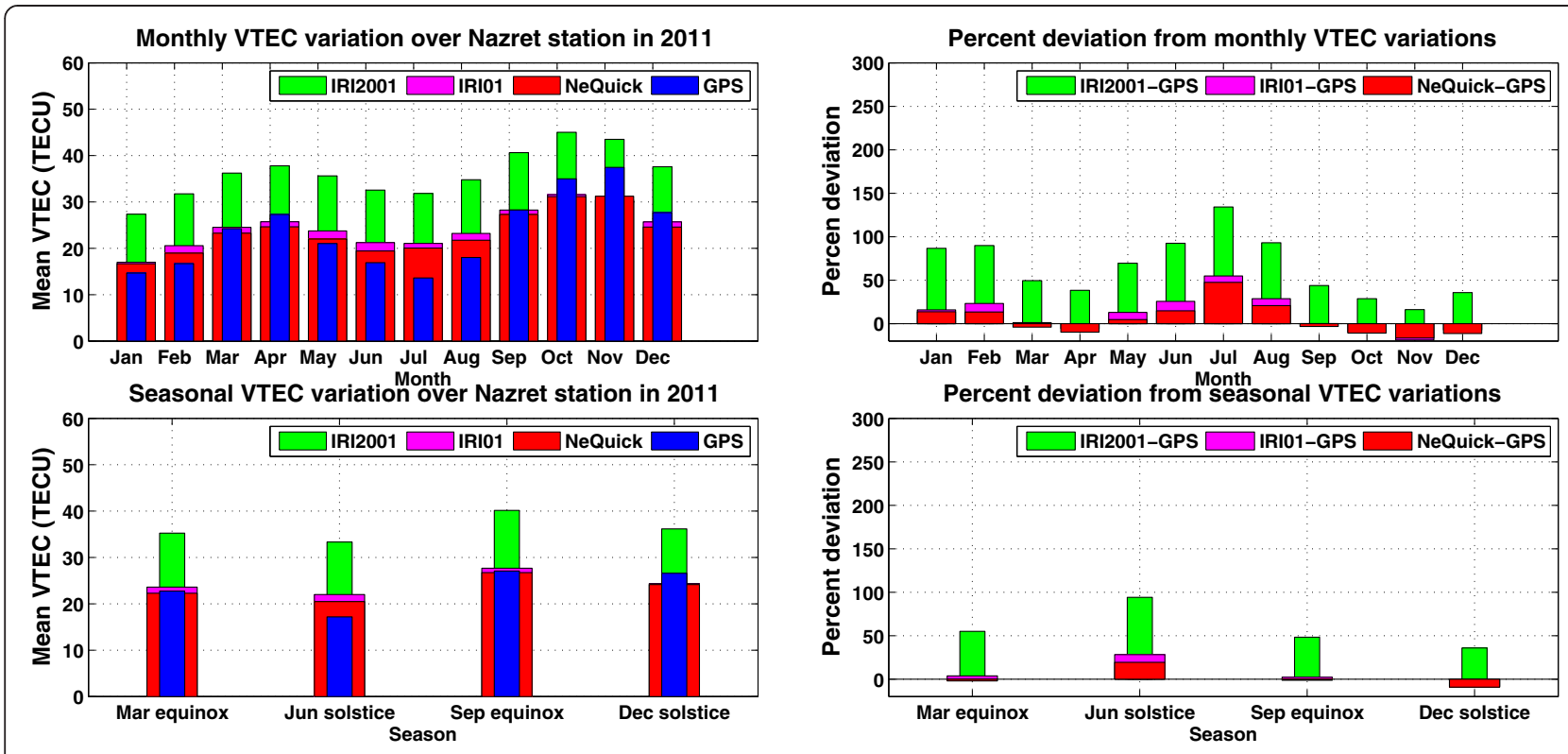

Fig. 7 Monthly and seasonal VTEC variations and validation of the IRI-2012 model over Nazret (station 2) during 2011

VTEC values by the model decreases as the Sun shifts from low to high solar activity (see Figs. 5, 6, and 7). This could be due to a misrepresentation of solar activity trends in the IRI model for the height maximum of the F2 layer (hmF2) (Bilitza et al. 2012). According to their findings, the discrepancy in the IRI model increases when solar activity moves toward a solar minimum; however, good agreement between the IRI model and ionosonde data of the hmF2 is observed during solar maximum years. Hence, the authors conclude that the sunspot number (Rz12) is not a good index to describe ionospheric conditions during the solar minimum, particularly for the recent solar minimum, and they recommend using the ionospheric index (IG12) for the hmF2 model instead. Furthermore, Kakinami et al. (2012) describe that the overestimation of the TEC by the IRI model increases with a decrease of EUV irradiance (during low solar activity) and decreases with an increase of EUV (during high solar activity). As shown in Figs. 5, 6, and 7, as the Sun moves from relatively low (2009) to high (2011) solar activity, the modeled VTEC values increase more slowly than the measured values. As a result, the performance of the IRI-2012 model in estimating the monthly and seasonal VTEC variations improves as we traverse from 2009 to 2011. Moreover, the overall monthly variation of the VTEC shows that it is generally better to use the model with the NeQuick option for topside electron density.

\section{Seasonal variation of VTEC and performance of the IRI-2012 model}

The results for seasonal VTEC variations are shown in Figs. 5, 6, and 7. The highest and lowest measured and modeled seasonal VTEC values are observed for the March equinox and the June solstice, respectively, during 2009 and 2010 (bottom left panels of Figs. 5 and 6). Figure 7 shows that the highest and lowest measured and modeled VTEC values are observed for the September equinox and the June solstice, respectively, during 2011 (bottom left panel of Fig. 7).

According to Johnson (1963), Torr and Torr (1973), and Rishbeth and Setty (1961), the lowest VTEC observed during the June solstice is possibly due to the asymmetric heating of the two hemispheres, which results in transportation of neutral constituents from the summer to the winter hemisphere, thereby reducing the recombination rate (or lose of electrons). This may account for an increase of the electron concentration during the winter. Furthermore, Earth's magnetic field is believed to guide plasma from the summer to the winter hemisphere. The semi-annual plasma change at low latitudes is caused by semi-annual changes in neutral composition of the atmosphere. At solstice, the atmosphere is generally more mixed due to summer upwelling and winter downwelling, as well as transport of gases from the summer to the winter hemisphere. This can result in a lower ionization crest value during the summer solstice than during the winter solstice (Bhuyan and Borah 2007; Wu et al. 2004). In addition, there is a gradual increase of the VTEC values during the period of 2009-2011. This gradual increase may be associated with an increase in solar activity as indicated by an increase in sunspot numbers during 2010 and 2011. The mean annual values of sunspot numbers during the period of 2009-2011 were 3.1, 16.5, and 55.7, respectively (see http://www.sidc.be/ 
sunspot-data/). Thus, during the period of very low solar activity (2009), the ionospheric TEC built up slowly, resulting in low TEC values (with relative maxima around midday). In 2010 and 2011, however, the solar activity levels started to increase, which directly resulted in a higher overall ionospheric electron density, leading to higher VTEC values (especially during 2011). For instance, the measured VTEC values observed during 2011 are larger (by a factor of almost two) than those observed in 2009 over the same station (Nazret; see bottom left panels of Figs. 5 and 7).

The model with the NeQuick option for the topside electron density overestimates the VTEC values in all seasons during 2009 and 2010, with the highest overestimation being observed for the June and December solstices. On the other hand, the lowest overestimations are observed for the December solstice and March equinox (bottom right panels of Figs. 5 and 6). During 2011, except for the June solstice, the model is found to entirely underestimate the VTEC values, with the highest underestimation observed for the December solstice when the NeQuick option is used. Overestimation of the seasonal VTEC values by the model decreases as the Sun transitions from a very low to a high solar activity phase, as shown in Figs. 5, 6, and 7. This effect can clearly be observed for the equinoctial and December solstice months of 2011. Overall, using the NeQuick option for the topside electron density is better for modeling seasonal VTEC values.

\section{Conclusions}

Because of the unique geometry of the magnetic field near equatorial and low-latitude regions such as Ethiopia, the trans-ionospheric satellite communication system is affected by the accumulation of electrons in the upper atmosphere. In this paper, observed VTEC variations and the capacity of the IRI-2012 model to estimate diurnal, monthly, and seasonal VTEC variations over Ethiopian regions during the rising phase of solar cycle 24 (20092011) were discussed in detail. The results reveal that the highest diurnal VTEC peak values are generally observed during equinoctial months, while the lowest peak values are observed during the June solstice months. In addition, the highest and the lowest monthly VTEC values are observed during the equinoctial and the June solstice months, respectively. Although the model overestimates VTEC values for most hours, it generally performs well in estimating diurnal VTEC values, especially just after the midnight hours (0000-0300 UT, 0300-0600 LT). The monthly and seasonal modeled VTEC values are larger than the corresponding measured values for 2009 and 2010 when all topside options are used. However, as the Sun transitions from very low to high solar activity, overestimation of the monthly and seasonal VTEC values by the model decreases. This may be due to a misrepresentation of solar activity trends in the IRI hmF2 model. Consequently, the performance of the model in estimating the monthly and seasonal mean VTEC values improves with the change from relatively low (2009) to high (2011) solar activity. The overall results show that using the IRI-2012 model with the NeQuick option for the topside electron density is generally better in estimating diurnal, monthly, and seasonal VTEC variations.

\section{Competing interests}

The author declares that he has no competing interests.

\section{Acknowledgements}

The data for daily sunspot numbers, GPS, and the IRI-2012 model described in this paper are freely available at http://www.sidc.be/sunspot-data/, http://facility. unavco.org/data/dai2/app/dai2.html, and http://omniweb.gsfc.nasa.gov/vitmo/ iri2012-vitmo.html, respectively. Hence, the author is very grateful to UNAVCO, NOAA, and NASA for providing their GPS, daily sunspot number, and online IRI-2012 model data, respectively.

Received: 12 March 2015 Accepted: 21 August 2015

Published online: 02 September 2015

\section{References}

Abdu MA, Batista IS, de Souza JR (1996) An overview of IRI-observational data comparison in American (Brazilian) sector low latitude ionosphere. Adv Space Res 18(6):13-22

Asmare Y., T. Kassa, M. Nigussie (2014) Validation of IRI-2012 TEC model over Ethiopia during solar minimum (2009) and solar maximum (2013) phases. Adv Space Res, 1582-1594, http://dx.doi.org/10.1016/j.asr.2014.02.017

Bhuyan PK, Borah RR (2007) TEC derived from GPS network in India and comparison with IRI. Adv Space Res 39:830-840

Bilitza D (1990) International Reference lonosphere 1990. NSSDC 22-90, Nation Space Science Data Center, Greenbelt

Bilitza D, Brown SA, Wang MY, Souza JR, Roddy PA (2012) Measurements and IRI model predictions during the recent solar minimum. J Atmos Sol-Terr Phys 86:99-106

Bilitza D, Altadill D, Zhang Y, Mertens C, Truhlik V, Richards P, McKinnell L, Reinisch BB (2014) The International Reference Ionosphere 2012-a model of international collaboration. J Space Weather Space Clim 4:A07. doi:10.1051/ swsc/2014004

Ciraolo L, Azpilicueta F, Brunini C, Meza A, Radicella SM (2007) Calibration errors on experimental slant total electron content (TEC) determined with GPS. J Geodesy 81:111-120

Ezquer RG, López JL, Scidá LA, Cabrera MA, Zolesi B, Bianchi C, Pezzopane M, Zuccheretti E, Mosert M (2014) Behaviour of ionospheric magnitudes of $\mathrm{F} 2$ region over Tucumán during a deep solar minimum and comparison with the IRI 2012 model predictions. J Atmos Sol-Terr Phys 107:89-98

Gao Y, Liu Z (2002) Precise ionospheric modelling using regional GPS network data. J Glob Pos Syst 1(1):18-24

Gulyaeva TL, Jayachandran B, Krishnankutty TN (2004) Latitudinal variation of ionospheric slab thickness. Adv Space Res 33:862-865

Hansen A, Blanch J, Walter T (2000) lonospheric correction analysis for WAAS quiet and stormy. ION GPS, Salt Lake City, pp 634-642

Hofmann-Wellenhof B, Lichtenegger H, Collins J (1992) Global Positioning Systems theory and practice. Springer-Verlag Wien, New York

loannides, R.T., H.J. Strangeways (2000) lonosphere-induced errors in GPS range finding using MQP modelling, ray-tracing and Nelder-Mead optimization. Millennium Conference on Antennas and Propagation, AP2000, vol. II, Davos, 404-408

Johnson FS (1963) Composition changes in the upper atmosphere. In: Thrane E (ed) Electron density distributions in the ionosphere and exosphere. North-Holland, Amsterdam, pp 81-84

Kakinami Y, Liu JY, Tsai LC (2012) A comparison of a model using the FORMOSAT-3/COSMIC data with the IRI model. Earth Planets Space 64:545-551 
Klobuchar JA, Parkinson BW, Spilker JJ (1996) lonospheric effects on GPS, in global positioning system: theory and applications. American Institute of Aeronautics and Astronautics, Washington D.C

Komjathy A, Langley RB (1996) The effect of shell height on high precision ionospheric modelling using GPS. In: Proceedings of the 1996 IGS Workshop, Silver Spring, MD., pp 193-203

Kumar S, Tan E, Razul S, Samson C, Slingh D (2014) Validation of the IRI-2012 mode with GPS-based ground observation over a low-latitude Singapore station. Earth Planets Space 66:7. doi:10.1186/1880-5981-66-17

Kumar S, Tan E, Murti D (2015) Impacts of solar activity on performance of the IRI-2012 model predictions from low to mid latitudes. Earth Planets Space 67:42. doi:10.1186/s40623-015-0205-3

Luhr H, Xiong C (2010) IRI-2007 model overestimates electron density during the 23/24 solar Minimum. Geophys Res Lett 37:L23101. doi:10.1029/ 2010GL045430

Mannucci AJ, Wilson BD, Yuan DN, Ho CH, Lindqwister UJ, Runge TF (1998). A global mapping technique for GPS-derived ionospheric total electron content measurements. Radio Sci 33:565-582. doi:10.1029/97RS02707

Matsushita S, Campbell WH (1967) Physics of geomagnetic phenomena, vol 1. Academic Press, New York

McNamara LF (1985) The uses of total electron content measurements to validate empirical models of the ionosphere. Adv Space Res 5(7):81-90

Misra P, Enge P (2006) Global positioning system signals, measurements and performance, Secondth edn. Ganga-Jamuna Press, Lincoln

Nigussie, M., S.M. Radicella, B. Damtie, B. Nava, E. Yizengaw, K. Groves (2013) Validation of the NeQuick 2 and IRI-2007 models in East-African equatorial region. J Atmos Sol-Terr Phys, http://dx.doi.org/10.1016/j.jastp.2013.04.016

Norsuzila Y, Abdullah M, Ismail M, Zaharim A (2009) Model validation for total electron content (TEC) at an equatorial region. Eur J Sci Res 28(4):642-648

Olwendo OJ, Baki P, Mito C, Doherty P (2012a) Characterization of ionospheric GPS total electron content (GPSTEC) in low latitude zone over the Kenyan region during a very low solar activity phase. J Atmos Sol-Terr Phys 84-85:52-61

Olwendo, O.J., P. Baki, C. Mito, P. Doherty (2012b) Comparison of GPS TEC variations with IRI-2007 TEC prediction at equatorial latitudes during a low solar activity (2009-2011) phase over the Kenyan region. J Adv Space Res, http://dx.doi.org/10.1016/j.asr.2012.08.001

Oyekola OS (2012) Equatorial vertical plasma drifts and the measured and IRI model-predicted F2-layer parameters above Ouagadougou during solar minimum. Earth Planets Space 64:577-593

Rawer K, Ramakrishnan S, Bilitza D (1978) International Reference lonosphere 1978. International Union of Radio Science, URSI Special report, Brussels, Belgium

Reddy C (2002) Study of space weather effects using GPS. In: Proceedings 2002, GPS in Atmospheric Sciences. India International Centre, New Delhi

Rios VH, Medina CF, Alvarez P (2007) Comparisons between IRI predictions and digisonde measurements at Tucuman. J Atmos Sol-Terr Phys 69:569-577

Rishbeth HC, Setty SK (1961) The F-layer at sunrise. J Atmos Terr Phys 20:263

Sardon E, Rius A, Zarraoa N (1994) Estimation of the transmitter and receiver differential Biases and the ionospheric total electron content from Global Positioning System observations. Radio Sci 29:577-586

Sethi NK, Dabas RS, Sarkar SK (2011) Validation of IRI-2007 against TEC observation during low solar activity over Indian sector. J Atmos Terr Phys 73:751-759

Tariku YA (2015) Patterns of GPS-TEC variation over low-latitude regions (African sector) during the deep solar minimum (2008 to 2009) and solar maximum (2012 to 2013) phases. Earth Planets Space 67:35. doi:10.1186/ s40623-015-0206-2

Torr MR, Torr DG (1973) The seasonal behavior of the F2-layer of the ionosphere J Atmos Terr Phys 35:22-37

Wu CC, Fry CD, Liu JY, Liou K, Tseng CL (2004) Annual TEC variation in the equatorial anomaly region during the solar minimum: September 1996-August 1997. J Atmos Terr Phys 66:199-207

\section{Submit your manuscript to a SpringerOpen ${ }^{\odot}$ journal and benefit from:}

- Convenient online submission

- Rigorous peer review

- Immediate publication on acceptance

- Open access: articles freely available online

- High visibility within the field

- Retaining the copyright to your article

Submit your next manuscript at $>$ springeropen.com 